\title{
A Mutation of the Glucocorticoid Receptor in Primary Cortisol Resistance
}

\author{
Diana M. Malchoff, * Adam Brufsky, * George Reardon,, Patrick McDermott, * \\ Emmanuel C. Javier, * Claes-Hakan Bergh, * David Rowe, ${ }^{*}$ and Carl D. Malchoff* \\ * Departments of Medicine and Surgery, University of Connecticut Health Center, Farmington, Connecticut 06030-1850; \\ ${ }^{\ddagger}$ St. Francis Hospital and Medical Center, Hartford, Connecticut 06105; and \\ ${ }^{\S}$ Department of Pediatrics, University of Connecticut Health Center, Farmington, Connecticut 06030
}

\section{Abstract}

The precise molecular abnormalities that cause primary cortisol resistance have not been completely described. In a subject with primary cortisol resistance we have observed glucocorticoid receptors ( $h G R$ ) with a decreased affinity for dexamethasone. We hypothesize that a mutation of the hGR glucocorticoid-binding domain is the cause of cortisol resistance. Total RNA isolated from the index subject's mononuclear leukocytes was used to produce first strand hGR cDNAs, and the entire hGR cDNA was amplified in segments and sequenced. At nucleotide 2,317 we identified a homozygous $A$ for $G$ point mutation that predicts an isoleucine (ATT) for valine (GTT) substitution at amino acid 729. When the wild-type hGR and hGR-Ile 729 were expressed in COS-1 cells and assayed for $\left[{ }^{3} \mathrm{H}\right]-$ Dexamathasone binding, the dissociation constants were $0.799 \pm 0.068$ and $1.54 \pm 0.06 \mathrm{nM}(\operatorname{mean} \pm \mathrm{SEM})(P<0.01)$, respectively. When the wild-type hGR and hGR-Ile 729 were expressed in CV-1 cells that were cotransfected with the mouse mammary tumor virus long terminal repeat fused to the chloramphenicol acetyl transferase (CAT) gene, the hGR-Ile 729 conferred a fourfold decrease in apparent potency on dexamethasone stimulation of CAT activity. The isoleucine for valine substitution at amino acid 729 impairs the function of the hGR and is the likely cause of primary cortisol resistance in this subject. (J. Clin. Invest. 1993.91:1918-1925.) Key words: primary cortisol resistance - glucocorticoid receptor mutation • isosexual precocious pseudopuberty $\bullet$ polymerase chain reaction - hypercortisolism

\section{Introduction}

Investigations of hormone resistance syndromes have classically yielded critical information concerning the mechanisms of hormone action. Primary cortisol resistance, first described by Vingerhoeds et al. (1), is a rare inherited disorder characterized by hypercortisolism without Cushingoid features. Clinical manifestations, if any, are secondary to excess circulating

This work was presented in part at the 1990 National Meeting of the Association of American Physicians, Washington, DC, and the 1991 National Meeting of the Endocrine Society, Washington, DC.

Address correspondence and reprint requests to Dr. C. Malchoff, Department of Surgery, University of Connecticut Health Center, 263 Farmington Ave., Farmington, CT 06030-1110.

Received for publication 15 April 1992 and in revised form 3 September 1992.

J. Clin. Invest.

(c) The American Society for Clinical Investigation, Inc.

0021-9738/93/05/1918/08 \$2.00

Volume 91, May 1993, 1918-1925 nonglucocorticoid adrenal steroids (1-10), which cause hypertension with hypokalemia (2) and/or signs of androgen excess $(7,9,10)$. Abnormalities of the human glucocorticoid receptor (hGR) ${ }^{1}$ number $(4,8,10)$, affinity for DNA (5), affinity for glucocorticoids $(2,9,10)$, and translocation to the nucleus (6) have been described. The molecular basis for this disorder has been determined for one subject (11) but is generally unknown.

We recently described a 6-7/12-yr-old boy with primary cortisol resistance and isosexual precocious pseudopuberty resulting from excess adrenal androgen secretion (9). Dexamethasone binding to hGR of intact fresh mononuclear leukocytes (MNL) revealed a $K_{\mathrm{d}}$ two- to threefold greater than controls and normal binding capacity (9). The hGR is compartmentalized. The two major functional domains are the DNA-binding domain, which is in the mid-region of the molecule, and the glucocorticoid-binding domain, which is at the carboxyl terminus (12-16). Since the ligand-binding affinity in this subject is decreased, we hypothesize that primary cortisol resistance results from a mutation of the glucocorticoid-binding domain of the hGR. We now describe a point mutation of the hGR mRNA that predicts a change in the primary structure of the glucocorticoid-binding domain and alters hGR function.

\section{Methods}

Subjects. The index subject was a 6-7/12-yr-old Hispanic boy with isosexual precocious pseudopuberty. The clinical and biochemical evidence for primary cortisol resistance has been described elsewhere (9). The mother of the index subject is a 26-yr-old Hispanic woman with no known medical problems including hirsutism, hypertension, or infertility. The father of the index subject was unavailable for analysis but is a first cousin of the index subject's mother. One source of control RNA was fresh MNL from a healthy unaffected adult. The other source of control RNA was early passage explant skin fibroblasts from an unaffected 10 -yr-old child, which were maintained in continuous culture in DME supplemented with $5 \%$ FCS. The study was approved by the Institutional Review Board at the University of Connecticut Health Center.

Binding of $\left[6,7-{ }^{3} \mathrm{H}\right]$ dexamethasone $\left(\left[{ }^{3} \mathrm{H}\right] \mathrm{Dex}\right)$ to glucocorticoid receptors of intact $M N L$. MNL were prepared from the index subject and his mother by Ficoll-Hypaque density gradient centrifugation (9). Binding of $\left[{ }^{3} \mathrm{H}\right] \operatorname{Dex}(50 \mathrm{Ci} / \mathrm{mmol}$; New England Nuclear, Cambridge, MA) to the hGR of intact MNL and analysis of results was performed as previously described (9).

$R N A$ extraction and $c D N A$ production. Table I summarizes the relevant characteristics of the hGR structure and the primers used to investigate the hGR cDNA sequence. Total RNA was extracted from MNL or fibroblasts by the acid-guanidinium-phenol-chloroform method of

1. Abbreviations used in this paper: CAT, chloramphenicol acetyl transferase; $\left[{ }^{3} \mathrm{H}\right]$ Dex, $\left[6,7-{ }^{3} \mathrm{H}\right]$ dexamethasone; hGR, human glucocorticoid receptor; MNL, mononuclear leukocytes. 
Table I. Summary of hGR Structure and Amplification Primers with Corresponding Nucleotides and Amino Acids

\begin{tabular}{lll}
\hline \multicolumn{1}{c}{ Nucleotide } & Amino acid & \multicolumn{1}{c}{ Significance } \\
\hline $1-4,800$ & $1-777$ & Entire hGR cDNA \\
$1-132$ & None & 5' untranslated region \\
$133-2,463$ & $1-777$ & Entire hGR coding region \\
$2,464-4,800$ & None & 3' untranslated region \\
$1,365-1,599$ & $411-489$ & DNA-binding domain \\
$1,714-2,463$ & $528-777$ & Glucocorticoid-binding domain \\
as 2,599-2,634 & $3^{\prime}$ untranslated & Reverse transcriptase primer \\
& region & \\
as $1,260-1,294$ & $376-387$ & Reverse transcriptase primer \\
$34-59$ & $5^{\prime}$ untranslated & GluR5, PCR primer \\
& region & \\
$57-75($ A at 69$)$ & $5^{\prime}$ untranslated & GluR14, PCR primer, creating \\
& region & a new Taq1 restriction site \\
$449-473$ & $106-113$ & GluR7, PCR primer \\
as 538-562 & $135-143$ & GluR6, PCR primer \\
$1,151-1,175$ & $339-348$ & GluR11, PCR primer \\
as $1,248-1,276$ & $372-381$ & GluR13, PCR primer \\
$1,574-1,598$ & $480-488$ & GluR4, PCR primer \\
as $1,633-1,657$ & $501-509$ & GluR9, PCR primer \\
as 2,526-2,550 & $3^{\prime}$ untranslated & GluR3', PCR primer \\
$2,236-2,260$ & region & \\
as 2,361-2,379 & & GluR10, PCR primer \\
& & PCRS4, sequencing primer \\
\hline & & \\
\hline
\end{tabular}

Chomczynski and Saachi (17) and precipitated twice with ethanol before use. First-strand cDNAs were synthesized from this RNA by standard methods (18). To prepare hGR cDNAs for the carboxyl half of the molecule, we used a 35-mer oligonucleotide primer complementary to nucleotides $2,599-2,634$, which are in the $3^{\prime}$ untranslated region of the alpha form of the hGR cDNA (19), to prime specific first-strand cDNA synthesis ( Table I and Fig. 1). A 35-mer oligonucleotide complementary to nucleotides $1,260-1,294$ was used to prime specific firststrand cDNA synthesis upstream of the middle of the molecule ( Table I and Fig. 1). In both cases $5 \mu \mathrm{g}$ of total RNA was incubated for $60 \mathrm{~min}$ at $37^{\circ} \mathrm{C}$ with $2.5 \mu \mathrm{g} \mathrm{35-mer} \mathrm{oligonucleotide} \mathrm{in} 50 \mu \mathrm{l}$ of buffer containing $50 \mathrm{mM}$ Tris ( $\mathrm{pH} 8.3$ ), $75 \mathrm{mM} \mathrm{KCl}, 3 \mathrm{mM} \mathrm{MgCl}, 10 \mathrm{mM}$ DTT, 500 $\mu \mathrm{M}$ dNTPs, and $250 \mathrm{U}$ MMuLV reverse transcriptase (Bethesda Research Laboratories, Gaithersburg, MD).

Polymerase chain reaction (PCR) amplification of the $h G R c D N A$. The primers and strategy for the PCR amplification of the hGR cDNA are shown in Table I and Fig. 1. The coding region of the carboxyl half of the molecule (including the DNA-binding and glucocorticoid-binding domains) was amplified with the template being the cDNA that had been prepared using the primer complementary to nucleotides $2,599-$ 2,634 . To PCR amplify the region coding for the glucocorticoid-binding domain, one tenth of the appropriate cDNA synthesis reaction ( 5 $\mu$ ) was mixed with $12.5 \mathrm{pmol}$ each of 25-mer oligonucleotides GluR4 and GluR3' (Table I and Fig. 1), which flanked a 976-bp region of the hGR cDNA coding for the glucocorticoid-binding domain (Fig. $2 \mathrm{~A}$ ). The reaction was brought to $100 \mu$, with the final buffer containing 50 $\mathrm{mM}$ Tris ( $\mathrm{pH} 8.3$ ), $1.5 \mathrm{mM} \mathrm{MgCl}, 0.01 \%$ gelatin, $200 \mu \mathrm{M} \mathrm{dNTPs}$, and $2.5 \mathrm{U}$ Taq polymerase (20). 30 cycles of heating to $94^{\circ} \mathrm{C}$ for $1 \mathrm{~min}$, cooling to $50^{\circ} \mathrm{C}$ for $1 \mathrm{~min}$, and heating to $72^{\circ} \mathrm{C}$ for $3.5 \mathrm{~min}$ were performed on a thermal cycler (model 2600; Perkin-Elmer Cetus Instruments, Norwalk, CT) with a 7 -min incubation at $72^{\circ} \mathrm{C}$ after the 30th cycle. The successful amplification of a specific 976-bp fragment was determined by electrophoresis of a $10-\mu 1$ aliquot of the reaction on a 5\% TBE-polyacrylamide gel (21) and staining with ethidium bromide. Alternatively, a 311 -bp fragment of hGR cDNA was PCR ampli- fied from $10 \mu$ l of first-strand hGR cDNA by the above methods using oligonucleotides GluR 10 and GluR3 (Table I and Fig. 1). To amplify the region that codes for the hGR DNA-binding domain, a 506-bp fragment of the hGR cDNA was PCR amplified from $10 \mu \mathrm{l}$ of the appropriate first-strand hGR cDNA by the above methods using oligonucleotides GluR9 and GluR11 (Table I and Fig. 1).

To amplify the remainder of the molecule, the cDNA prepared with the primer complementary to nucleotides $1,260-1,294$ was used as the template. Using GluR7, GluR13, and the PCR reagents described above, an 827-bp DNA fragment was amplified with the following conditions: 30 cycles of heating to $94^{\circ} \mathrm{C}$ for $1 \mathrm{~min}$, cooling to $50^{\circ} \mathrm{C}$ for 1 min, and heating to $72^{\circ} \mathrm{C}$ for $3.5 \mathrm{~min}$. Using GluR5, GluR6, and the PCR reagents and conditions described above, a 528-bp DNA fragment that included the 5 ' untranslated region was amplified. $3 \mu$ l of this reaction was reamplified using primers GluR 14 and GluR6 and the same reaction conditions to produce a 502-bp fragment. GluR 14 introduces a new TaqI restriction enzyme site at position 67 by substituting an $\mathrm{A}$ for $\mathrm{G}$ at position 69 . This site is used for subcloning.

DNA sequencing. The amplified 976-bp fragment carrying the coding region for the glucocorticoid-binding domain was isolated from the PCR mixture by electroelution (21), cleaved with TaqI (nucleotides 1,602 and 2,500), and ligated into the AccI site of pBS SK + (Stratagene, Inc., La Jolla, CA). The amplified 311-bp fragment was isolated by electroelution, cleaved with NsiI (nucleotide 2,309) and TaqI (nucleotide 2,500), and ligated into the PstI and AccI sites of pBS SK+. The 506-bp fragment carrying the region coding for the DNA-binding domain was cleaved with StyI (nucleotide 1,233) and EcoRI (nucleotide 1,628 ) and ligated into the XbaI and EcoRI sites of pBS SK + . The amplified 827-bp fragment was cleaved with HindIII (nucleotides 490 and 1,044$)$ and the resultant fragment ligated into pBS SK+ cleaved with HindIII. This fragment was also cut with BstYI (nucleotides 915 and 1,237) and ligated into pBS SK + cleaved with BamHI. The 502-bp fragment was cleaved with TaqI (nucleotides 67 and 526) and ligated into pBS SK + cleaved with AccI. The recombinant plasmids were used to transform Escherichia coli. Recombinant plasmid DNAs were isolated from single-banded $\mathrm{CsCl}$ preparations of single recombinant bacterial colonies and sequenced by the dideoxy method (22), using $\left[{ }^{35} \mathrm{~S}\right] \mathrm{dATP}$ and the universal primer, T3 primer, and internal primers.

Where indicated, the 311-bp PCR reactions $(90 \mu \mathrm{l})$ were precipitated twice with ammonium acetate and ethanol and sequenced directly using $\sim 50 \mathrm{ng}\left(2 \times 10^{5} \mathrm{cpm}\right)$ of a $\left[{ }^{32} \mathrm{P}\right] \mathrm{dCTP}$-labeled internal hGR-specific oligonucleotide (PCRS4, Fig. 1) as a sequencing primer (22).

All sequencing reactions were analyzed on denaturing 6\% TBEurea polyacrylamide gels. At least 10 recombinant clones were se-

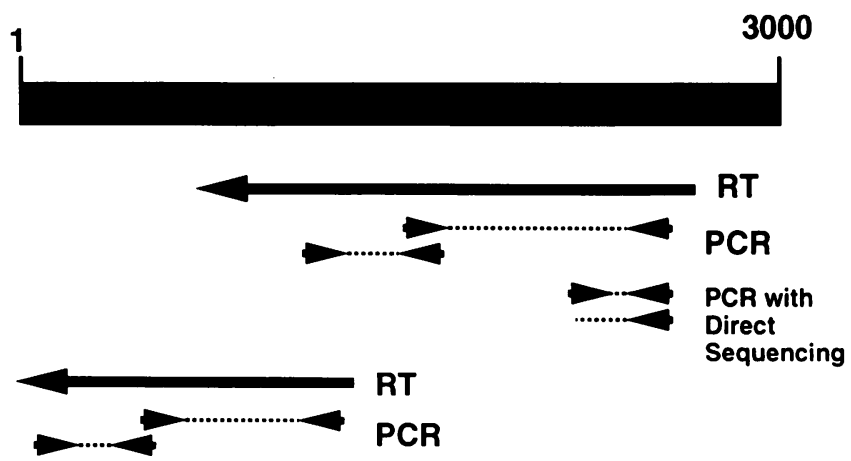

Figure 1. Strategy for PCR amplification and sequencing of the hGR cDNA. The first 3,000 nucleotides of the hGR mRNA are indicated by the top thick black line. The strategy for reverse transcription $(R T)$ and PCR amplification of cDNA are indicated. These fragments were subcloned and sequenced as described in Methods. The region containing the mutation at cDNA nucleotide 2,317 was also sequenced by direct sequencing of PCR products as indicated. 


\section{Genomic DNA Sequence}

Wild Intron H...tcattaccatatcttctcttgcag GTGGTT...Exon $9 \alpha$ Mutant Intron H...tcattaccatatcttctcttgcag GTGATT...Exon $9 \alpha$ (A at 2317)

\section{PCR Primer RE2 \\ TCATTACCATATCTTCTCETGCAGG}

\section{PCR AMPLIFIED DNA}

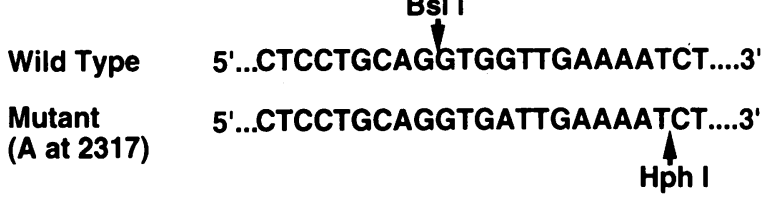

Figure 2. Strategy for detecting the A for $\mathrm{G}$ substitution at nucleotide 2,317 in genomic DNA. The A for G substitution at hGR cDNA nucleotide 2317 (underlined) is near the border of the ninth exon and the $\mathrm{H}$ intron and creates a new HphI site in the genomic DNA. The appropriate regions of both the wild-type and the mutant sequences are shown. The upstream primer (RE2) used for PCR amplifying this region of the genomic DNA is identical to the wild-type sequence except for a $\mathrm{C}$ that is substituted for a $\mathrm{T}$ at the position indicated by a box. This substitution creates a new restriction site in the resultant fragment when the wild-type genomic DNA is amplified but not when the mutant genomic DNA is amplified. The resultant fragment from PCR amplification of the wild-type genomic DNA contains the BslI (CCNNNNN/NNGG) restriction site, but not the HphI site. The resultant fragment from PCR amplification of the mutant genomic DNA contains the HphI (GGTGANNNNNNNN/) restriction site, but not the BslI site. The uncut PCR amplified fragment is $96 \mathrm{bp}$ when either the wild-type or mutant genomic DNA is used as the template. Cleavage of the fragment amplified from the wild-type genomic DNA with Bsl I yields a 72-bp fragment, and cleavage of the fragment amplified from the mutant genomic DNA with HphI yields a 60 -bp fragment.

quenced for the patient, his mother, and the two controls, and at least two independent PCR reactions were sequenced from each of the four subjects directly. Sequence was compared with the published sequence of the hGR cDNA (19).

Analysis of genomic DNA. The genomic DNA was isolated from MNL of the index subject, his mother, and 20 unaffected normal controls by the method of Gross-Bellard et al. (23). This DNA was used as a template for PCR amplification of the region of the genomic DNA carrying the A for $\mathrm{G}$ substitution at cDNA nucleotide position 2,317. Fig. 2 shows the sequence of the intron-exon junction (24), the selection of the PCR primers, and the strategy for analyzing the genomic DNA for the hGR cDNA mutation at position 2,317. This mutation introduces a new HphI cleavage site not present in the wild-type DNA. Primer RE2 carries single-base mismatch to create a Bsl I restriction site in the wild-type genome but not in the genome of the index subject. 50 ng of genomic DNA was mixed with 12.5 pmol each of the primers (Table I and Fig. 2). The reaction was brought to $100 \mu \mathrm{l}$ with the final buffer containing $50 \mathrm{mM}$ Tris ( $\mathrm{pH} 8.3$ ), $1.5 \mathrm{mM} \mathrm{MgCl}_{2}, 0.01 \%$ gelatin, $200 \mu \mathrm{M}$ dNTPs, and $2.5 \mathrm{U}$ Taq polymerase (20). 30 cycles of heating to $94^{\circ} \mathrm{C}$ for $1 \mathrm{~min}$, cooling to $51^{\circ} \mathrm{C}$ for $0.75 \mathrm{~min}$, and heating to $72^{\circ} \mathrm{C}$ for 1.5 min with a $4-\mathrm{min}$ incubation at $72^{\circ} \mathrm{C}$ after the 30 th cycle were used to amplify a 96-bp fragment carrying the region of interest. This PCR product was precipitated with $7.5 \mathrm{M}$ ammonium acetate and $100 \%$ ethanol and divided into three equal aliquots; one was left uncut, one was cut overnight with 5 U Bsl I (New England Biolabs, Beverly, $\mathrm{MA}$ ), and one was cut overnight with $4 \mathrm{U}$ of $\mathrm{HphI}$ (New England Biolabs). Reaction conditions were according to the specifications of the manufacturer. The products were separated on a $6 \%$ TBE-polyacrylamide minigel and stained with ethidium bromide.

Preparation of expression vectors. An expression vector carrying the identified mutation of the hGR cDNA was prepared from the an expression vector linking the RSV LTR to full length wild-type hGR cDNA (pRShGR $\alpha$ ), which was graciously provided by Dr. Stanley M. Hollenberg (The Salk Institute, San Diego, CA; reference 15). The 976-bp PCR-amplified cDNA coding for the entire glucocorticoidbinding domain was cleaved with Nsil (nucleotide 2,309) and Aval $(2,380)$ to generate a 72 -bp fragment containing the $A$ for $G$ substitution at nucleotide 2,317. This was ligated into the corresponding Nsil and Aval sites of the BstXI-XhoI fragment of the pRShGR $\alpha$, which had been subcloned into $\mathrm{pBS} \mathrm{SK}+$. The ClaI-Xhol fragment of this construct was ligated into the corresponding ClaI and Xhol sites of the $\mathrm{pRShGR} \alpha$ to create an expression vector for the mutant hGR-Ile 729 . This vector was sequenced in its entirety to be sure that no other mutations had been introduced inadvertently.

The expression vector, pMTVCAT, which contains the mouse mammary tumor virus long terminal repeat (MTV) fused to the cDNA for chloramphenicol acetyltransferase (CAT), was graciously provided by Dr. Stanley Hollenberg.

Transfection of mammalian cells. To investigate the ligand-binding properties of wild-type hGR and hGR-Ile 729, these receptors were expressed in COS- 1 cells by the DEAE-dextran transfection method (15). COS- 1 cells were grown at $37^{\circ} \mathrm{C}$ in DMEM supplemented with $10 \%$ FCS in an atmosphere of $5 \% \mathrm{CO}_{2}$ and $95 \%$ air to a density of $50 \%$ in 10-cm culture dishes. Media was aspirated, cells were washed once with PBS, and refed with $4 \mathrm{ml}$ of DMEM containing $10 \%$ NuSerum (Collaborative Research, Bedford, MA). The expression vectors, which had been purified using two $\mathrm{CsCl}-\mathrm{EtBr}$ equilibrium gradients, were dissolved in Tris-buffered saline at a concentration of $0.25 \mu \mathrm{g} / \mu \mathrm{l}$, and $40 \mu \mathrm{l}$ of this solution was mixed with $80 \mu \mathrm{l}$ of $10 \mathrm{mg} / \mathrm{ml}$ DEAEdextran in Tris-buffered saline and added dropwise to each plate of COS- 1 cells. After a 4-h incubation at $37^{\circ} \mathrm{C}$, the medium was aspirated from the plates, and the cells were shocked by incubating with $5 \mathrm{ml}$ of $10 \%$ DMSO in PBS for $1 \mathrm{~min}$ at $20^{\circ} \mathrm{C}$. The DMSO solution was aspirated. The cells were washed with $5 \mathrm{ml}$ of PBS, and $10 \mathrm{ml}$ of complete medium was added to each plate. After being incubated for $48 \mathrm{~h}$, the cells were harvested, lysed by freezing and thawing in TEDGM ( 10 $\mathrm{mM}$ Tris, $1.5 \mathrm{mM}$ EDTA, $0.5 \mathrm{mM}$ dithiothreitol, $3 \%$ glycerol, and 10 $\mathrm{mM}$ sodium molybdate), centrifuged at $100,000 \mathrm{~g}$ for $60 \mathrm{~min}$ at $4{ }^{\circ} \mathrm{C}$, and the supernatant, which had a final protein concentration of $\sim 2-5$ $\mathrm{mg} / \mathrm{ml}$, was assayed for dexamethasone binding.

To investigate the ability of the wild-type hGR and mutant hGR-Ile 729 to stimulate gene transcription, the expression vector for each receptor was cotransfected with pMTVCAT into CV-1 cells by the calcium phosphate method (15). CV-1 cells were grown in MEM supplemented with $10 \%$ FCS at $37^{\circ} \mathrm{C}$ in 10 -cm plates and split $24 \mathrm{~h}$ before transfection. For each plate $10 \mu \mathrm{g}$ of pMTVCAT and the expression vector for the normal or mutant hGR were dissolved in $450 \mu \mathrm{l}$ sterile water and combined with $50 \mu \mathrm{l} 2.5 \mathrm{M} \mathrm{CaCl}_{2}$. This solution was then added to $500 \mu$ l of $2 \times$ Hepes-buffered saline, allowed to precipitate for $20 \mathrm{~min}$ at $20^{\circ} \mathrm{C}$, and distributed evenly over a $10-\mathrm{cm}$ plate of cells. After $6 \mathrm{~h}$ the medium was aspirated. The cells were shocked with $2 \mathrm{ml}$ of $10 \%$ DMSO in PBS for $3 \mathrm{~min}$ at $20^{\circ} \mathrm{C}$, washed twice with $5 \mathrm{ml} \mathrm{PBS,}$ and fed with $10 \mathrm{ml}$ of complete medium containing the indicated concentration of dexamethasone. Complete medium containing dexamethasone at the indicated concentrations was changed at $24 \mathrm{~h}$. The cells were harvested at $48 \mathrm{~h}$, lysed by freezing and thawing in $0.25 \mathrm{M}$

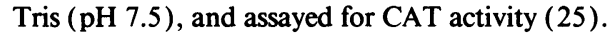

Functional assays of expressed glucocorticoid receptors. Specific binding of $\left[{ }^{3} \mathrm{H}\right]$ Dex to wild-type and mutant hGR expressed in COS-1 cells was determined by the dextran-coated charcoal method (26). About $200 \mu \mathrm{g}$ of cytosolic protein was incubated in a final volume of $0.1 \mathrm{ml}$ TEDGM buffer with [ ${ }^{3} \mathrm{H}$ ] Dex at concentrations from 0.1 to 25 $\mathrm{nM}$ at $4^{\circ} \mathrm{C}$ for $16 \mathrm{~h}$ in the absence and presence of a 1,000 -fold excess of unlabeled dexamethasone. To determine the $K_{d}$ of the hGR for cortisol, binding was performed at a concentration of $\left[{ }^{3} \mathrm{H}\right]$ Dex equal to its 
$K_{\mathrm{d}}$, and cortisol concentrations from 3 to $1,000 \mathrm{nM}$. To separate bound from free ligand, $50 \mu \mathrm{l}$ of a solution containing $1 \%$ charcoal and $0.01 \%$ dextran was mixed with the binding reaction and, after 10 min at $4^{\circ} \mathrm{C}$, the mixture was centrifuged for $2 \mathrm{~min}$ on a microcentrifuge. The supernatant was assayed on a liquid-scintillation counter. Specific binding was calculated by subtracting nonspecific binding from total binding and the results were analyzed by Scatchard analysis. The $K_{d}$ for cortisol was calculated from the concentration of cortisol required to inhibit [ ${ }^{3} \mathrm{H}$ ]Dex binding by $50 \%$ and equilibrium binding equations for a competitive inhibitor (27).

CAT activity was measured by the diffusion method of Eastman (25). The final reaction mixture contains $125 \mathrm{mM}$ Tris $(\mathrm{pH}=7.8)$, $1.25 \mathrm{mM}$ chloramphenicol, and $0.28 \mu \mathrm{M}$ acetyl $\mathrm{CoA}(1.4 \mathrm{Ci} / \mathrm{mmol})$ in a volume of $250 \mu \mathrm{l}$. The cytosols from three separate transfection experiments were treated with the indicated concentrations of dexamethasone in triplicate and assayed.

\section{Results}

Fig. 3 shows the Scatchard analysis of the binding of $\left[{ }^{3} \mathrm{H}\right]$ Dex to intact MNL hGR of the mother of the index subject. The normal range (mean $\pm 2 \mathrm{SD}$ ) for the $K_{\mathrm{d}}$ is $1.4-3.4 \mathrm{nM}$, and the normal range for maximum binding capacity is $5.3-7.7 \mathrm{fmol} /$ $10^{6}$ cells. The $K_{\mathrm{d}}$ derived for the index subject and his mother were $6.4 \pm 0.8($ mean $\pm \mathrm{SEM} ; n=4)$ and $6.2 \pm 1.2 \mathrm{nM}$ ( mean $\pm \mathrm{SEM} ; n=3$ ), respectively. The maximum binding capacities are $6.5 \pm 0.5$ and $5.7 \pm 0.7 \mathrm{fmol} / 10^{6}$ cells, respectively. The dissociation constants of both the index subject and his mother were significantly different from normal $(P<0.01)$, and the maximum binding capacities were within the normal range. The dissociation constants of the index subject and his mother were not significantly different from each other.

Using the PCR, we amplified in four overlapping segments the entire cDNA coding for the hGR from the index subject and from two unrelated and unaffected controls. The 976-bp fragment carried the coding region for the entire glucocorticoid-binding domain and the 506-bp fragment carried the coding region for the entire DNA-binding domain. All samples demonstrated a specific DNA fragment of appropriate molecular weight after amplification. All four fragments were subcloned and entirely sequenced.

Sequencing of the index subject's hGR cDNA fragment demonstrated two $A$ for $\mathrm{G}$ substitutions not present in a cloned

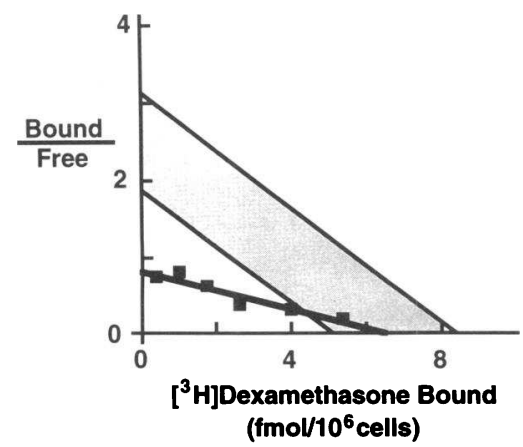

Figure 3. Scatchard analysis of $\left[{ }^{3} \mathrm{H}\right]$ Dex binding to hGR of intact MNL from the mother of the index subject. Binding of $\left[{ }^{3} \mathrm{H}\right]$ Dex to the hGR of intact MNL obtained from the mother of the index subject and 12 unrelated control subjects was determined as described in Methods.

The Scatchard analysis of these results is shown. The binding of the mother's MNL hGR is represented by the solid squares. The shaded area represents the $95 \%$ confidence limits ( mean \pm 2 SD) of the control binding. The $95 \%$ confidence intervals of the slopes are reported in the results.
hGR cDNA (19). The A for G substitution at nucleotide 1,011 was found in all eight clones from the index subject and changes the codon for amino acid 293 from AAG to AAA. Both these codons predict a lysine in this position in the final protein sequence. Therefore, this substitution is not expected to change the amino acid sequence of the hGR. A second A for $G$ substitution of the index subject's hGR cDNA was identified at nucleotide 2,317 (Fig. 4). This alteration was present in nine of nine independent $\mathrm{pBS}-\mathrm{hGR}$ recombinant plasmids. In addition, the $A$ at position 2,317 was the only nucleotide present in directly sequenced PCR products from the index subject. The mutation was not present in nine of nine pBS-hGR recombinant plasmids sequenced from the two controls (Fig. 4), both of which demonstrated the normal $\mathrm{G}$ at this position. The $\mathrm{A}$ for $G$ substitution at position 2,317 predicts an alteration in codon 729 of the hGR cDNA from GTT to ATT. This would change amino acid 729 from valine to isoleucine when the mRNA is expressed as protein. No other mutations were found.

We next PCR-amplified a 311-bp fragment of the hGR cDNA from the mother of the index subject and a normal control. This cDNA fragment was selected to include the site of the mutation at position 2,317 . The mother's cDNA was found to have both $\mathrm{a} G$ and an $A$ at position 2,317 (Fig. 4). The $A$ was present in 4 of 10 recombinant pBS-hGR plasmids, and the $G$ was present in the remaining 6 recombinant pBS-hGR plasmids. In addition, the mother's cDNA was found to have a G/A doublet at position 2,317 when the 311-bp hGR cDNA fragment was directly sequenced after PCR amplification. The mutation was not present in seven of seven pBS-hGR recombinant plasmids sequenced from the unaffected controls.

Fig. 5 is an example of the restriction enzyme analysis of the amplified genomic DNA from the index subject and one normal control. In both cases a 96-bp fragment is obtained from the PCR amplification. The fragment amplified from the index subject is cut completely by HphI to yield a 60-bp fragment, but this fragment is not cut by BslI. This demonstrates that his genomic DNA is homozygous for the $A$ for $G$ substitution at cDNA nucleotide 2,317, which creates a new HphI site and causes a loss of the BslI site. The fragment amplified from the control subject is cut completely by BslI to yield a 72-bp fragment, but this fragment is not cut by HphI. Analysis of genomic DNA from 20 unrelated controls gave this same result. Therefore, both alleles of each control genomic DNA have a $G$ at nucleotide 2,317, not an A. Not shown is the fragment amplified from the mother of the index subject, which is cut partially by both enzymes, indicating that she is heterozygous and carries a copy of both the mutant and wild-type alleles.

The expression vector for the hGR-Ile 729 was prepared as described in the Methods section, and the wild-type hGR and hGR-Ile 729 were expressed in tissue culture. Fig. 6 is an example of the Scatchard analysis of $\left[{ }^{3} \mathrm{H}\right]$ Dex binding to the wildtype hGR and mutant hGR-Ile 729 that had been expressed in COS- 1 cells. It illustrates the decreased affinity of hGR Ile-729 for $\left[{ }^{3} \mathrm{H}\right]$ Dex. The binding analysis was performed in duplicate on the cytosols from four separate transfection experiments. The dissociation constants for the wild-type hGR and hGR-Ile 729 were $0.799 \pm 0.068$ and $1.54 \pm 0.06 \mathrm{nM}$ ( mean $\pm \mathrm{SEM}, n=4$, $P<0.01$ ), respectively. The maximum binding capacities were $1,030 \pm 160$ and $1,130 \pm 210 \mathrm{fmol} / \mathrm{mg}$ protein $(P=\mathrm{NS})$, respectively. The dissociation constants of the wild-type hGR and hGR-Ile 729 for cortisol were $11.2 \pm 2.8$ and $32.2 \pm 8.4 \mathrm{nM}$, respectively $(n=3, P<0.01)$. 

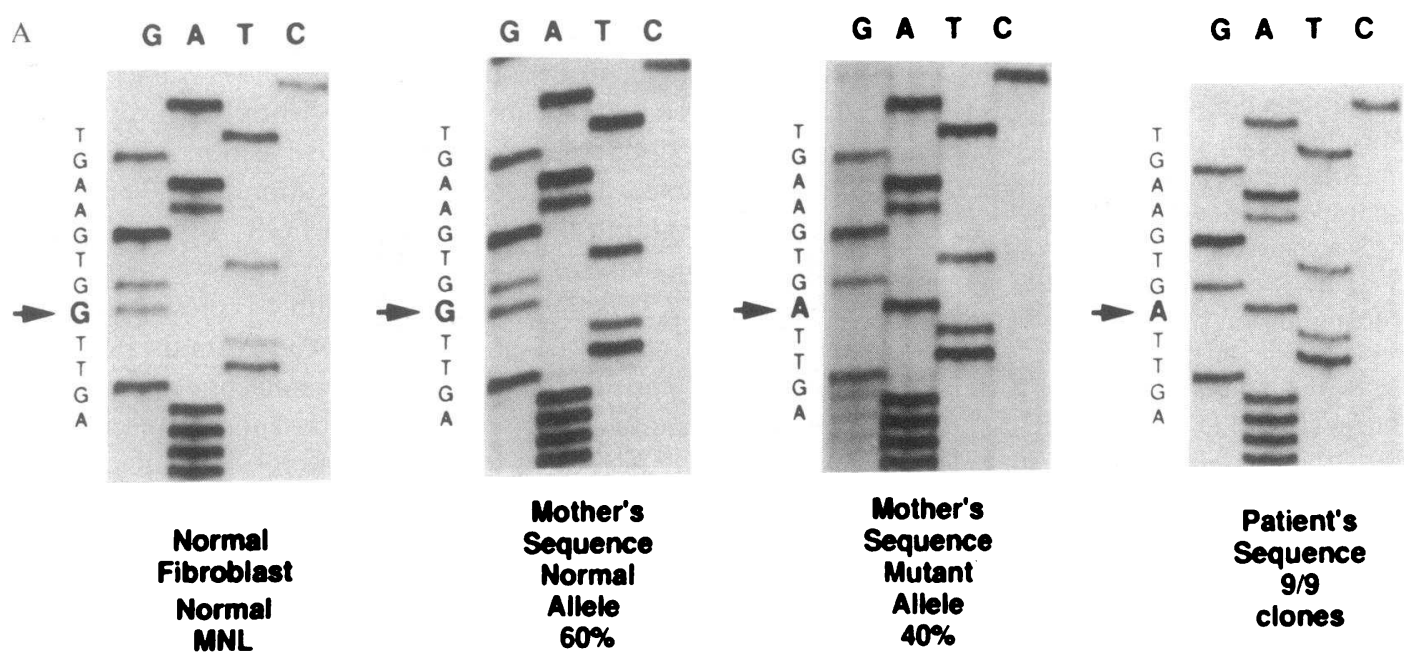

Figure 4. Sequence of the hGR mutation. $(A)$ Experimental result. Sequencing of recombinant plasmids was performed as described in Methods, and the region of interest is shown. The altered nucleotide at position 2,317 is indicated by the arrow. $(B)$ Amino acid and cDNA sequences immediately surrounding the muta-

Normal Sequence ATG CAT GAA GTG GTT GAA AAT CTC CTT Met His Glu Val Val Glu Asn Leu Leu

Amino Acid Position 725

729

733

Mutant Sequence

ATG CAT GAA GTG ATT GAA AAT CTC CTT Met His Glu Val lle Glu Asn Leu Leu

The stimulation of CAT activity by dexamethasone in CV1 cells cotransfected with pMTVCAT and expression vectors for the wild-type hGR and hGR-Ile 729 is shown in Fig. 7. The mean shift in the concentration of dexamethasone required for half maximal stimulation of CAT activity was $4.0 \pm 0.9$-fold ( $P$
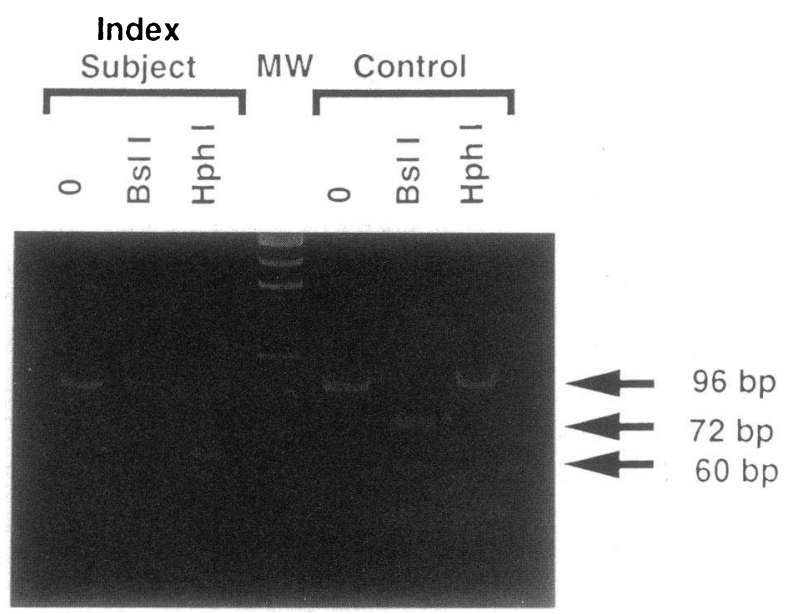

Figure 5. Cleavage of PCR-amplified genomic DNA with BslI and HphI. Genomic DNA from the index subject and a normal control was PCR amplified using primers RE2 and RE3 as described in Methods. Equal aliquots were incubated without restriction enzymes, with Bsl I, or HphI, as indicated and analyzed on with 6\% PAGE and ethidium bromide staining. MW indicates molecular weight markers. PCR amplification of the genomic DNA yielded a 96-bp fragment using either genomic DNA as template. The PCR-amplified DNA from the index subject was cleaved completely with $\mathrm{HphI}$ to yield a 60 -bp fragment but was not cleaved by BslI. The PCR-amplified DNA from this and 19 other unrelated control subjects was cleaved completely with BslI to yield a 72-bp fragment but was not cleaved by HphI.
$<0.05$ ), when the mutant hGR-Ile 729 expression vector was substituted for the wild-type hGR expression vector. The maximum CAT activity in response to $30 \mathrm{nM}$ dexamethasone increased linearly with the log of the amount of the hGR and hGR-Ile 729 expression vectors transfected up to $10 \mu \mathrm{g}$ of expression vector.

\section{Discussion}

Fig. 8 summarizes the sequencing of the index subject's hGR cDNA and indicates the relative cDNA and amino acid location of the mutation at hGR cDNA nucleotide 2,317 . This A for $\mathrm{G}$ substitution predicts the substitution of an isoleucine for a valine at hGR amino acid 729, which is located in the glucocorticoid-binding domain. Not shown is the A for G substitu-

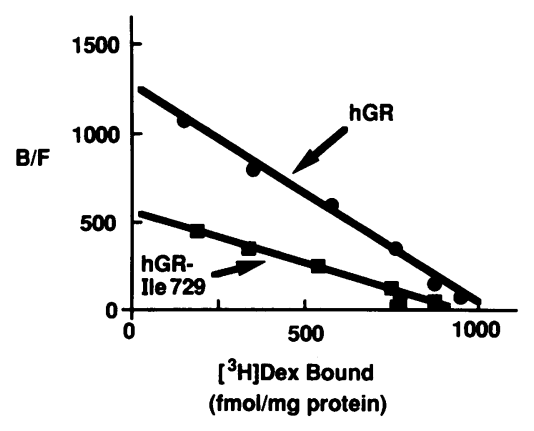

Figure 6. Scatchard analysis of $\left[{ }^{3} \mathrm{H}\right]$ Dex binding to the wild-type hGR and hGR-Ile 729. COS- 1 cells were transfected with the wildtype hGR or hGR-Ile 729 expression vector using the DEAE-dextran method, and the cytosol was assayed for $\left[{ }^{3} \mathrm{H}\right]$ Dex binding. Cytosol from control COS-1

cells transfected with pBS KS+ DNA does not bind $\left[{ }^{3} \mathrm{H}\right]$ Dex, indicating an absence of hGR in COS- 1 cells. The results shown are of a single experiment performed in duplicate. Four separate transfection experiments using four different transfection products for both the hGR and hGR-Ile 729 were assayed in duplicate and the apparent dissociation constants were $0.799 \pm 0.068$ and $1.54 \pm 0.06 \mathrm{nM}$ (mean \pm SEM $)(P<0.01)$, respectively. 


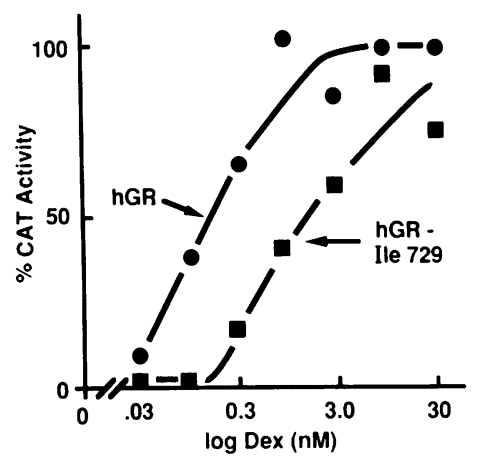

Figure 7. Stimulation of CAT activity by dexamethasone. CV-1 cells were cotransfected with MTV-CAT and either hGR or hGR-Ile 729 expression vectors by the calcium phosphate method and incubated for $48 \mathrm{~h}$ with dexamethasone at the indicated concentrations. Supernatants from the cells were assayed for CAT

activity as described in Methods. The mean activities from three separate experiments performed in duplicate are plotted. The CAT activity in cells transfected with hGR and hGR-Ile 729 is significantly different $(P<0.05)$ at dexamethasone concentrations of $0.03,0.1$, $0.3,1.0$, and $3.0 \mathrm{nM}$. The concentration of dexamethasone required for half maximal stimulation of CAT activity was $4.0 \pm 0.9$-fold ( $P$ $<0.05$ ) greater when the cells were transfected with the hGR-Ile 729 expression vector than when they were transfected with the hGR expression vector. Maximum CAT activity was $250 \pm 35 \mathrm{pmol} / \mathrm{mg}$ protein per $h$. No CAT activity was detected in the absence of dexamethasone or if the expression vector for MTV-CAT was transfected with $\mathrm{pBS} \mathrm{KS}+$.

tion at nucleotide 1,011 . This mutation does not predict a change in the amino acid sequence of the hGR and therefore is not expected to cause cortisol resistance. The entire hGR cDNA was sequenced and no other mutations were found. The evidence in this manuscript supports the hypothesis that the mutation at nucleotide 2,317 is the cause of decreased dexamethasone-binding affinity and subsequently primary cortisol resistance in the index subject.

The studies of $\left[{ }^{3} \mathrm{H}\right]$ Dex binding to the hGR of the intact MNL shows an affinity abnormality of the glucocorticoid receptor from both the index subject and his mother. These results suggest that cortisol resistance is an inherited defect and has not arisen as a new mutation in the index subject. Since the affinity of the glucocorticoid receptor is affected, an abnormality in the glucocorticoid-binding domain of the index subject is expected.

The $G$ to $A$ missense point mutation at nucleotide 2,317 was not an artifact of our reverse transcription and/or amplification procedures, since it was found in two family members and not in normal controls. Restriction enzyme analysis of the PCR-amplified genomic DNA from the index subject, his mother, and normal controls provides further evidence that the mutation is not an artifact of our procedures. These results demonstrate the mutation in the index subject and his mother in a specific and sensitive assay of genomic DNA. The mutation was not found in 20 unrelated controls.

It is likely that the index subject is homozygous for the mutation at nucleotide 2,317 . The only nucleotide found at position 2,317 of his hGR cDNA was an A, and the parents of the index subject are believed to be first cousins. In addition, analysis of the genomic DNA supports the conclusion, since the DNA fragment that was amplified from genomic DNA was cleaved by HphI, and not BslI. This mutation is apparently heterozygous in the mother, since approximately half of her hGR cDNA clones had a $G$ at position 2,317, and half had an A. The analysis of the genomic DNA also supports this conclusion, since the amplified DNA could be partially cut by both restriction enzymes. The father was not available for analysis but is likely to have contributed the second mutant allele to the index subject. He could have contributed a nonexpressed or null allele to the index subject. However, this possibility is unlikely in light of the normal receptor-binding capacity of the index subject's hGR, which implies a normal amount of receptor protein (9).

Several lines of evidence support the hypothesis that hGRIle 729 is the cause of primary cortisol resistance in the index subject. First, the location of the mutation in the glucocorticoid-binding domain predicts that the receptor will have a decreased affinity for dexamethasone, as we had observed in the MNL hGR of the index subject. In vitro experiments with transfected cloned animal and human hGR cDNAs have demonstrated that the terminal 250 amino acids of the receptor are responsible for the glucocorticoid-binding activity, which can be altered by single amino acid changes $(13-15,28)$. Since the identified mutation is in the glucocorticoid-binding domain as expected, it is likely to be responsible for the decreased dexamethasone affinity of the hGR. Second, no other mutation that predicts a change in the amino acid sequence of the hGR was found. Third, the functional activities of the hGR-Ile 729 receptor expressed in tissue culture were very similar to those observed in vivo. When expressed in mammalian cells the hGR-Ile 729 is functionally abnormal. The dissociation constant for $\left[{ }^{3} \mathrm{H}\right]$ Dex is about twice normal. This corresponds well with the two- to threefold increase in dissociation constant of the native MNL hGR of the index subject (9). The fourfold decrease in the apparent potency of dexamethasone to stimulate hGR-mediated gene transcription corresponds well with the in vivo response of ACTH to dexamethasone. A daily dose of $4 \mathrm{mg}$ of dexamethasone was required to decrease the serum cortisol concentration to $<140 \mathrm{nmol} /$ liter $(5 \mu \mathrm{g} / \mathrm{dl})$ in the index subject (9). This is about five times as much as is nor-

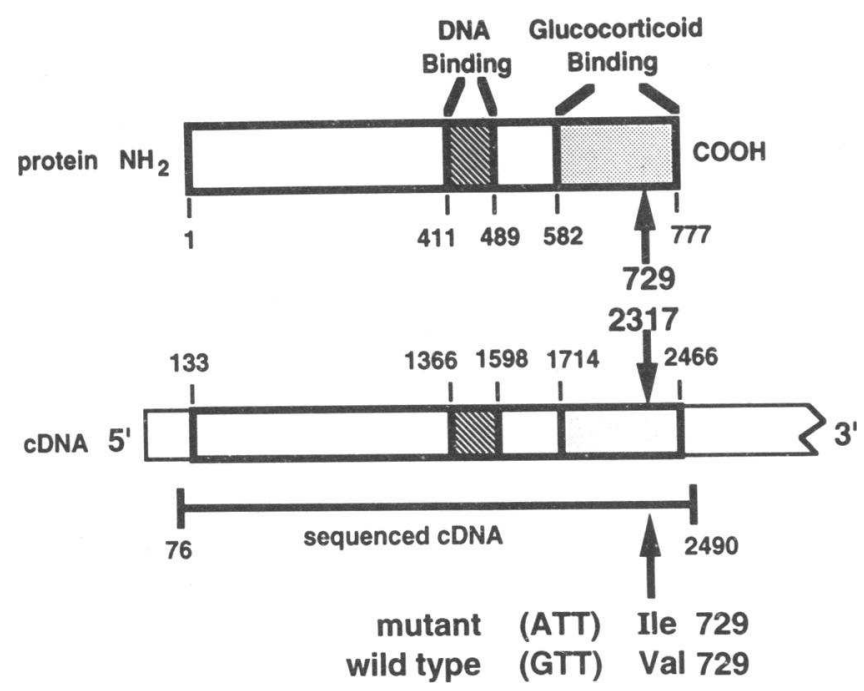

Figure 8. Summary of the hGR mutation in relationship to the hGR functional domains. The hGR protein structure is summarized in the top bar with the numbers indicating the relevant amino acids. The lower bar summarizes the hGR cDNA with the numbers indicating the corresponding nucleotides. The line below this indicates the portion of the hGR cDNA sequenced in this study. The entire hGR coding region was sequenced. The arrows indicate the site of the hGR mutation that causes primary cortisol resistance. 
mally expected to produce the same effect. Fourth, similar findings have been demonstrated in other disorders of steroid hormone resistance. In another kindred with primary cortisol resistance, a single amino acid change of the glucocorticoid-binding domain causes cortisol resistance (11). In addition, single amino acid alterations of the human androgen receptor (29) and human thyroid hormone receptor (30) cause end organ resistance syndromes to each of these hormones. Fifth, studies of androgen-resistance syndromes have identified two regions of the androgen receptor ligand-binding domain that frequently carry mutations in subjects with decreased androgen receptor affinity for testosterone and subsequent androgen resistance (31). The mutation that we suspect to cause cortisol resistance is located in a region of the glucocorticoid-binding domain analogous to one of these two regions of the androgen receptor ligand-binding domain. As in the androgen-resistance model, a mutation in this region of the glucocorticoid-binding domain causes hormone resistance by altering the receptor affinity for its ligand. Sixth, the mother of the index subject is heterozygous for the mutation that the index subject is apparently homozygous. Therefore, it is expected that she would be less clinically affected than the index subject. Indeed, this is the case, since she has no hirsutism, infertility, or other clinical evidence of androgen excess. Taken together these six lines of evidence strongly support the hypothesis that an A for $G$ substitution at nucleotide 2,317 is responsible for the syndrome of primary cortisol resistance in the index subject.

A mutation causing primary cortisol resistance has been reported in one other kindred. This mutation was at a different position in the glucocorticoid-binding domain and also was associated with a decreased hGR affinity for glucocorticoids. It was homozygous in the index subject and heterozygous in a family member who was less affected clinically (10). Interestingly, the mutation reported here is biochemically more conservative than most others that have been reported to cause cortisol resistance or other syndromes of steroid hormone resistance $(11,29,30)$.

This very conservative substitution of a neutral isoleucine for a neutral valine produces a surprisingly large change in receptor affinity for glucocorticoids and a clinical syndrome with cortisol resistance that is seemingly greater than anticipated from the change in dexamethasone binding. It should be noted that this is not complete resistance, since it can be overcome by large amounts of exogenous glucocorticoids (9). We and others have proposed that complete resistance may be incompatible with life (32). There are two possible explanations for the apparent discrepancy between the dexamethasonebinding affinity abnormality and the clinical abnormalities of the index subject (9). First, cortisol, the naturally occurring glucocorticoid, may bind less effectively to the mutant receptor than dexamethasone. Second, the mutant receptor may have more abnormal functions than just ligand binding. These possibilities are not mutually exclusive, and there is some evidence for both. The ratio of dissociation constants of the mutant receptor to that of the wild-type receptor is 1.9 for dexamethasone and 2.9 for cortisol. This indicates that the binding of the natural ligand is affected to a greater degree than binding of dexamethasone, a more potent glucocorticoid agonist. Therefore, the dexamethasone-binding studies may not accurately predict the magnitude of the clinical abnormalities, since cortisol is the naturally occurring glucocorticoid. It should also be noted that the valine at amino acid position 729 is present throughout evolution. Mouse (13), rat (33), and new world monkey (34) glucocorticoid receptors all normally contain a valine at the position equivalent to residue 729 of the human receptor. Thus, this amino acid may serve a key function in the mechanism of hGR action. Isoleucine has a slightly more bulky side chain than valine, and this may hinder glucocorticoid binding to the receptor. It has also been suggested that this region of the hGR may be important in receptor dimerization, which may promote hGR binding to the glucocorticoid regulatory elements (35). This mutation may interfere with dimerization, thereby inhibiting binding of the activated receptor to the DNA and contributing further to the clinical expression of cortisol resistance. It is attractive to hypothesize that this amino acid is bifunctional, since this may help to explain the apparent discrepancy between alterations in binding affinity of dexamethasone and the apparent potency of dexamethasone to stimulate gene transcription; the former is altered twofold whereas the latter is altered fourfold.

The results presented here do not explain why the dissociation constant of the MNL hGR from both the index subject and his mother are equal. It is possible that the binding assay is not sensitive enough to detect subtle differences. If the mutant and wild-type hGR bind independently, then a slightly curved Scatchard analysis is predicted. However, our visual analysis of the predicted Scatchard curve indicates that, with the sensitivity of the current binding assay, such a curve would be impossible to distinguished from a straight line. Alternatively, there may be unexpected interactions between receptors that influences their apparent binding affinities.

In summary, we have demonstrated an inherited point missense mutation of the hGR glucocorticoid-binding domain in a subject with primary cortisol resistance. This mutation was identified by sequencing cDNA prepared from mRNA and was subsequently demonstrated to be present in genomic DNA. This conservative mutation decreases the affinity of the expressed glucocorticoid receptor for glucocorticoids and impairs its ability to stimulate gene transcription. The magnitude of the changes observed in vitro in these studies are very similar to the magnitude of the changes observed previously in the patient. Taken together these results strongly support the hypothesis that homozygosity for this mutation causes the clinical and biochemical phenotype of primary cortisol resistance in the kindred under study. These studies also suggest that Val 729 of the hGR is critical for its normal function.

\section{Acknowledgments}

We thank Drs. Robert M. Carey, Alan Rogol, Lawrence G. Raisz, Mary Louise Stover, David Brandon, and D. Lynn Loriaux for their encouragement and helpful comments and Ms. Patricia Hart and Mr. Jonathan Korn for excellent technical assistance.

Supported by grants from the University of Connecticut Clinical Research Center, the University of Connecticut Health Center Research Foundation, and the Diabetes Research and Education Foundation, and National Institutes of Health grant 1R29DK 42840-01. C. H. Bergh was supported by a travel grant award from the Swedish Medical Research Council, the Swedish National Association against Heart and Chest Diseases, and the Swedish Society of Endocrinology.

\section{References}

1. Vingerhoeds, A. C. M., J. H. H. Thijssen, and F. Schwarz. 1976. Spontaneous hypercortisolism without Cushing's syndrome. J. Clin. Endocrinol. Metab. 43:1128-1133. 
2. Chrousos, G. P., A. C. M. Vingerhoeds, D. Brandon, C. Eil, M. Pugeat, M. DeVroede, D. L. Loriaux, and M. B. Lipsett. 1982. Primary cortisol resistance in man. A glucocorticoid receptor mediated disease. J. Clin. Invest. 69:1261-1269.

3. Chrousos, G. P., A. C. M. Vingerhoeds, D. L. Loriaux, and M. B. Lipsett 1983. Primary cortisol resistance: a family study. J. Clin. Endocrinol. Metab. $56: 1243-1245$

4. Iida, S., M. Gomi, K. Moriwaki, Y. Itoh, K. Hirobe, Y. Matsuzawa, S Katagiri, T. Yonezawa, and S. Tarui. 1985. Primary cortisol resistance accompanied by a reduction in glucocorticoid receptors in two members of the same family. J. Clin. Endocrinol. Metab. 60:967-971.

5. Nawata, H., K. Sekiya, K. Higuchi, K. Kato, and H. Ibayashi. 1987. Decreased deoxyribonucleic acid binding of a glucocorticoid-receptor complex in cultured skin fibroblasts from a patient with glucocorticoid resistance syndrome. J. Clin. Endocrinol. Metab. 65:219-226.

6. Bronnegard, M., S. Werner, and J. A. Gustaffson. 1986. Primary cortisol resistance associated with a thermolabile receptor in a patient with fatigue as the only symptom. J. Clin. Invest. 78:1270-1278.

7. Lamberts, S. W. J., D. Polderman, M. Zweens, and F. H. de Jong. 1986. Familial cortisol resistance: differential diagnostic and therapeutic aspects. $J$. Clin. Endocrinol. Metab. 63:1328-1333.

8. Gomi, M., S. Iida, M. Tsugawa, Y. Itoh, K. Moriawaki, and S. Yamashita. 1986. Decreased glucocorticoid receptors in cultured skin fibroblasts from a patient with primary cortisol resistance. N. Engl. J. Med. 314:1194.

9. Malchoff, C. D., E. C. Javier, D. M. Malchoff, T. Martin, A. Rogol, D. Brandon, D. L. Loriaux, and G. E. Reardon. 1990. Primary cortisol resistance presenting as isosexual precocity. J. Clin. Endocrinol. Metab. 70:503-507.

10. Lamberts, S. W. J., J. W. Koper, P. Biemond, F. H. den Holder, and F. H. de Jong. 1992. J. Clin. Endocrinol. Metab. 74:313-321.

11. Hurley, D. M., D. Accili, C. Stratakis, M. Karl, N. Vamvakopoilos, E. Rorer, K. Constantine, S. I. Taylor, and G. P. Chrousos. 1991. Mutation of the human glucocorticoid receptor gene in familial glucocorticoid resistance. J. Clin. Invest. 87:680-686.

12. Carlstedt-Duke, J., P. E. Stromstedt, O. Wrange, T. Bergman, J. Gustafsson, and H. Jornvall. 1987. Domain structure of the glucocorticoid receptor protein. Proc. Natl. Acad. Sci. USA. 84:4437-4440.

13. Danielsen, M., J. P. Northrup, and G. M. Ringold. 1986. The mouse glucocorticoid receptor: mapping of functional domains by cloning, sequencing and expression of wild-type and mutant receptor proteins. EMBO (Eur. Mol. Biol. Organ.) J. 5:2513-2522.

14. Evans, R. 1988. The steroid and thyroid hormone receptor superfamily. Science (Wash. DC). 240:889-895.

15. Giguere, V., S. M. Hollenberg, M. G. Rosenfeld, and R. M. Evans. 1986 Functional domains of the human glucocorticoid receptor. Cell. 46:645-652.

16. Rusconi, S., and K. Yamamoto. 1987. Functional dissection of the hormone and DNA binding activities of the glucocorticoid receptor. EMBO (Eur. Mol. Biol. Organ.) J. 6:1309-1315.

17. Chomczynski, P., and N. Saachi. 1987. Single-step method of RNA isolation by guanidinium-thiocyanate-phenol-chloroform extraction. Anal. Biochem. 162:1569-1571

18. D'Alessio, J. M., M. C. Noon, H. L. Ley, and G. F. Girard. 1987. One-tube double stranded cDNA synthesis using cloned MMuLV reverse transcriptase. BRL Focus. 9:1-4.
19. Hollenberg, S. M., C. Weinberger, E. S. Ong, G. Cerelli, A. Oro, R. Lebo, E. B. Thompson, M. G. Rosenfeld, and R. M. Evans. 1985. Primary structure and expression of a functional human glucocorticoid receptor cDNA. Nature (Lond.). 318:635-641.

20. Saiki, R. K. D. H Gelfand, S. Stoffel, S. J. Scharf, R. Higuchi, G. T. Horn, K. B. Mullis, and H. A. Erlich. 1988. Primer-directed enzymatic amplification of DNA with a thermostable DNA polymerase. Science (Wash. DC). 239:487-491.

21. Maniatis, T., E. F. Fritsch, and J. Sambrook. 1982. Polyacrylamide gel electrophoresis. In Molecular Cloning: A Laboratory Manual. Cold Spring Harbor Press, Cold Spring Harbor, NY. 173-177.

22. Eckert, R. I. 1989. DNA Sequencing. In Current Protocols in Molecular Biology. F. M. Ansubel, R. Brent, R. E. Kingston, D. D. Moore, J. G. Seidman, J. A. Smith, and K. Struhl, editors. Wiley Interscience, New York. 7.1.1-7.6.5.

23. Gross-Bellard, M., P. Oudet, and P. Chambon. 1973. Isolation of highmolecular-weight DNA from mammalian cells. Eur. J. Biochem. 36:32-38.

24. Encio, I. J., and S. D. Detera-Wadleigh. 1991. The genomic structure of the human glucocorticoid receptor. J. Biol. Chem. 266:7182-7188.

25. Eastman, A. 1987. An improvement to the novel rapid assay of chloramphenicol acetyl transferase gene expression. Biotechniques. 5:730.

26. Noma, K., D. Nakao, B. Sato, Y. Nishizawa, K. Matsumoto, and Y. Yamamura. 1980. Effect of molybdate on activation and stabilization of steroid receptors. Endocrinology. 107:1205-1211.

27. Cheng, V. C., and Prusoff, W. H. 1973. Relationship between the inhibition constant and the concentration of inhibitor which causes 50 per cent inhibition of an enzymatic reaction. Biochem. Pharmacol. 22:3099-3108.

28. Picard, D., S. J. Salser, and K. Yamamoto. 1988. A movable and regulable inactivation function within the steroid binding region of the glucocorticoid receptor. Cell. 54:1073-1080.

29. Lubahn, D. B., T. R. Brown, J. A. Simental, H. N. Higgs, C. J. Migeon, E. M. Wilson, and F. S. French. 1989. Sequence of the intron/exon junctions of the coding region of the human androgen receptor gene and identification of a point mutation in a family with complete androgen insensitivity. Proc. Natl. Acad. Sci. USA. 86:9534-9538.

30. Usala, S. J., G. E. Tennyson, A. E. Bale, R. W. Lash, N. Gesundheit, F. E. Wondisford, D. Accili, P. Hauser, and B. D. Weintraub. 1990. A base mutation of the $\mathrm{C}$-erbA $\beta$ thyroid hormone receptor in a kindred with generalized thyroid hormone resistance. J. Clin. Invest. 85:93-100.

31. McPhaul, M. J., M. Marcelli, S. Zoppi, J. E. Griffin, and J. D. Wilson 1992. Amino acid substitutions that cause androgen resistance cluster in short segments of the androgen receptor gene. Clin. Res. 40:251a. (Abstr.)

32. Javier, E. C., G. E. Reardon, and C. D. Malchoff. 1991. Glucocorticoid resistance and its clinical presentations. The Endocrinologist. 1:141-148.

33. Miesfield, R., S. Rusconi, P. J. Godowski, B. A. Maler, S. Okret, A Wilkstrom, J. Gustafsson, and K. R. Yamamoto. 1986. Genetic complementation of a glucocorticoid receptor deficiency by expression of cloned receptor cDNA. Cell. 46:389-399.

34. Brandon, D. D., A. J. Markwick, and D. L. Loriaux, D. L. 1989. Alterations in the functional domains of the glucocorticoid receptor gene from a glucocorticoid "resistant" new world primate. Endocr. Soc. 71st Annu. Meet. 1375a. (Abstr.)

35. Fawell, S. E., J. A. Lees, R. White, and M. G. Parker. 1990. Characterization and colocalization of steroid binding and dimerization activities in the mouse estrogen receptor. Cell. 60:953-960. 